\title{
QUALITY OF LIFE FOR PATIENTS AFTER CORONARY ARTERY BYPASS GRAFTING
}

\author{
Amal Bakr Abo-El-Ata ${ }^{1}$, Dina Al-tabey Sobeh ${ }^{2}$, Fairouz Mohamed Mansor $^{3}$ \\ Prof. of Medical Surgical Nursing ${ }^{1}$, Assist. Prof. of Medical Surgical Nursing ${ }^{2}$, \\ Demonstrator of Medical Surgical Nursing ${ }^{3}$; Faculty of Nursing-Port Said university
}

\begin{abstract}
Background: Quality of life (QOL) for patients after coronary artery bypass grafting $(\mathrm{CABG})$ is affected by Factors such as psychosocial, demographic factors and patients' related characteristics. Aim: This study aimed to assess quality of life for patients after coronary artery bypass grafting. Subjects and Method: A descriptive research design was utilized. Convenient sample of CABG patients (100) at outpatient clinics at both universal health insurance hospitals (Al-Salam and Al-Nasr) and private hospital (Ataa) at Port Said City. Tools: Tool I: It included three parts, part 1: Sociodemographic characteristics, part 2: Medical and surgical history, part 3: Short form survey 36 questions (SF-36) to assess quality of life. Results: This study showed that $74 \%$ of the patients had poor quality of life. Conclusion: It can conclude that about three-quarter of the studied patients had poor QOL, most affected domains are general health domain followed by social functioning domain then physical functioning domain and vitality. There was statistically significant relation between patients' QOL and their sex, educational level, work, marital status, income, floor number and presence of elevator. Also, there was statistically significant relation between patients' QOL and presence of diabetes, hypertension, hyperlipidemia, smoking, first time surgery and body mass index. Recommendation: The study recommended the event of cardiac rehabilitation program for patients.
\end{abstract}

Keywords: Coronary artery bypass grafting, quality of life 


\section{INTRODUCTION}

Coronary artery bypass grafting $\mathrm{CABG}$ is a common surgical procedure that enhance symptoms, survival and quality of life for patients with coronary artery disease. Unfortunately, patients' quality of life does not improve in all domains following CABG (Pac aric et al, 2020). "Not only the absence of illness and infirmity, but also the existence of physical, emotional, and social well-being," according to the World Health Organization (WHO). Quality of life (QoL) has become particularly relevant in medicine, social sciences, and health care to capture this multifaceted definition since it represents not only objective clinical or physiologic status, but also the patients' subjective impressions of the effect of a clinical condition on their lives, such as their ability to perform physical and social tasks, to feel content in their everyday lives, and to maintain satisfying interpersonal relationships (Perrotti et al, 2019).

The modern definition of patient care means that we are concerned not only about whether the patient is alive and how long he lives, but also with how he lives and how happy he is with his life. This is why, in its manifesto "The Vision of Health for All," published in 1993, the World Health Organization promotes slogans such as "Add Years to Life," as well as "Add Life to Years." This idea gives you an equivalence "In determining the prognosis of disease after an intervention, this definition places quality of life on an equal footing with survival. The way people assess their own health status and medical aspects of their lives is referred to as QOL. It is the most comprehensive way of assessing how fair a patient's treatment standards are. (Peric et al, 2017).

Most of the evidence on post coronary artery bypass surgery management focuses on medication and commitment to lifestyle change (increase physical activity, cessation of smoking and tobacco, and a healthy diet). Sparse evidence exists regarding the long-term impact of lifestyle change on outcomes of patients who underwent coronary artery bypass surgery CAD. Poorly Known about medication and lifestyle change may lead to the worsening of coronary artery disease after surgery. Noncompliance after surgery is a complex problem and a major health issue worldwide (Ibrahim, \&Abdalla, 2019).

\section{Significance of the study:}

According to the most recent WHO statistics, Coronary Artery Disease Deaths in Egypt reached 163,171 (29.38 percent) of total deaths in 2018. Egypt ranks 15th in the 
world with a death rate (WHO, 2018). The treatment of choice for patients with CAD is coronary artery bypass grafting $(\mathrm{CABG})$, which is widely used around the world. According to the World Health Organization, about 50,000 CABG surgeries are conducted in India each year, with more than 800,000 CABG surgeries performed worldwide. (Pulimala et al, 2020). In the United States, 219,000 CABG surgeries were conducted in 2010. (Albilasi, 2018). CABG has a 3\% overall mortality rate, while elective primary coronary bypass has a $1.7 \%$ mortality rate. Furthermore, there is the risk of a severe complication following surgery. As a result, assessing domains of quality of life for CABG patients is critical (Khalifa, Eisa, Bary, Ismail, \& Taha, 2018).

Nowadays, coronary artery diseases become big health problems and it is one of the main causes of mortality and impairment in patient daily activities in the world. Coronary artery bypass surgery is considered treatment of choice for patients with CAD as it enhances survival and quality of life but, the fear and anxiety of patients from this major surgery complications and changes in life style make challenge. Although coronary artery bypass surgery has positive effect in relieving angina and prolong life, coronary restenosis after $\mathrm{CABG}$, cerebrovascular and cardiovascular events, and new stenosis due to progression of atherosclerosis will still cause patients to be admitted to hospital again and post-operative complications affects quality of life for patients after surgery. So, it is important to assess domains of quality of life for CABG patients.

\section{AIM OF THE STUDY}

The aim of this study was to assess the quality of life for patients after coronary artery bypass grafting at outpatient clinics of hospitals in Port Said city (The universal health insurance and Private hospitals).

This will be achieved through the following research objective:

- Assess domains of quality of life for patients after coronary artery bypass grafting.

\section{Research question:}

- What is the effect of coronary artery bypass grafting on patient 'quality of life? 


\section{SUBJECTS AND METHOD}

\section{Technical design:}

The technical design included the study design, setting, subjects and tool of data collection.

\section{Research design:}

The design that was utilized in this study is a descriptive research design.

\section{Setting:}

The study was conducted at outpatient clinics of hospitals in Port Said city as follow:

a- The universal health insurance (Al-Nasr Specialist hospital) which have cardiac outpatient clinics two days weekly (Saturday and Thursday) and Al-salaam hospital which have cardiac outpatient four days weekly (Sunday, Wednesday, Thursday, Friday).

b- Private hospitals (Ataa hospital) which have cardiac outpatient clinics two days weekly (Saturday and Tuesday).

\section{Subjects}

Convenience sample of Coronary artery bypass grafting surgery patients came to outpatient clinics at Port Said hospitals in Port Said City at six months from May, 2020 and completed by end of October, 2020. The total number of patients was 100 (59 male and 41 female).

\section{Inclusion Criteria:}

Patients who completed 6 months or more after CABG surgery.

\section{Exclusion criteria:}

- $\quad$ Patients with communication disorder.

- $\quad$ Patients with coexisting diseases.

\section{Tools of data collection:}

Data for this study was collected using the following tool:

Tool (I): Patients' quality of life: This tool included three parts:

Part (1): Socio-demographic characteristics of the patients:

It includes socio-demographic characteristics of the patients under study as regards; age, sex, level of education, marital status, occupation, residence, family member number, weight, height, lifting condition and family income. 
Part (2): past medical and surgical history related:

It includes patients' past medical and surgical history related, (chronic disease (Diabetes Miletus, Hypertension, Coronary artery disease, Hyperlipidemia, heart failure, obesity and receiving treatment), past surgical history (cardiac catheterization, percutaneous coronary intervention, appendectomy, herniotomy and laminotomy) and patient present habits as smoking. This part developed by the researcher after reviewing and utilizing the most recent and relevant literature (Albilasi.etal.,2018), (Sun,Tu,Badr Eddeen,\& Liu, 2018), and (Majlessi, et al.,2019).

Part (3): Short form survey 36 questions (SF-36) to assess quality of life:

To assess quality of life, this tool adopted from (Ware\& Sherbourne, 1992). With 36 items spanning eight domains of QOL, the SF-36 short survey is a standardized tool for assessing generic health concepts. It contains ten items related to everyday tasks in the area of physical functioning., role limitation due to physical problems, which include 4 items., 5 items are related to general mental health., role limitation due to emotional problem which includes 3items, social functioning, which includes 2 items related to relationship with family and friends., General health, which include 6 items related to personal perception of patient health, bodily pain, which includes two items about the intensity of the patient's body pain, and The energy or vitality domain comprises four elements related to vitality, fatigue, and tiredness. This tool was originally written in English, then translated into Arabic before being re-translated into English.

Scoring system for QOL domains: The scaled scores on the SF-36 survey are the weighted sums of the questions in their respective segment. The scoring is done in two steps. To begin, pre-coded numeric values are recoded according to the scoring key provided; note that all items are scored, with a higher score indicating a better health condition. Furthermore, each item is rated on a scale of $0-100$, with 0 being the lowest and 100 being the highest possible scores. The 8 scale scores are generated in phase 2 by averaging items on the same scale. These scores were translated into percent scores for each domain of QOL based on a cut point of $60 \%$. (Silva, S., Santana, A., Silva, N., Novaes, M. (2019). If the percent score was equal to or greater than $60 \%$, the patient was considered to have a good quality of life, and if it was less, the patient was considered to have a poor quality of life. 


\section{Operational Design:}

The study, to be completed, has passed through different phases as follows: preparatory phase, content Validity and reliability, pilot study and field work.

\section{Preparatory phase:}

The researcher used books, journals, periodicals, magazines, and internet explorer to review relevant present, past, local, and foreign literature covering different aspects of the problem in order to better understand the problem and improve data collection tools.

\section{Content Validity:}

It was decided by (9) nursing and medical staff members' expertise. Their thoughts on the consistency and comprehensiveness of the questions and items on the sheets and tool were elicited.

\section{Reliability:}

The Cronbach alpha coefficient was used to evaluate the internal consistency of the developed method, which was used to assess its reliability. This tool's Cronbach's alpha value for Arabic type was 0.829 .

\section{Pilot Study:}

It was done to check the tool's validity and applicability, as well as estimate the time it would take to fill out the sheet. On ten percent (10) of CABG patients, the quality of life assessment was used. The findings of the pilot study were taken into account, as well as the revision of the tool by experts. Patients who took part in the pilot project were not included in the study.

\section{Field Work:}

This study's data was collected over a six-month period, starting in May 2020 and ending in October 2020. The researcher spent two days a week at outpatient clinics in the previous mentioned hospitals. The researcher then began the interview, which lasted about 20-25 minutes. Using the data collection tool, approximately 1-3 patients were interviewed at a time. 


\section{Administrative design:}

The Dean of the faculty of nursing at Port Said University sent an official letter to the director of universal health insurance, requesting his permission for data collection at cardiothoracic clinics at health insurance hospitals.

\section{Ethical Consideration:}

Following a clarification of the study's purpose and process, the health insurance director gave his approval to perform the study. The ethics and science research committee approved the protocol for this study. Patients' consent to participate in the study was obtained after the study was explained to them and they were assured that the data collected would be kept confidential and this information will be used only for the purpose of the study. The study participants were told by the researcher that they had the right to withdraw from the study at any time without penalty.

\section{Statistical design:}

The Epi-Info 6.04 computer software package was used for data entry, and the statistical analysis was performed with the statistical Package for Social Science (SPSS) version 11.0. For qualitative variables, descriptive statistics in the form of frequencies and percentages were used, while for quantitative variables, means and standard deviations were used.The chi-square test was used to compare qualitative variables. Fisher exact test was used if the predicted values in one or more cells in a $2 \times 2$ table were less than 5 . In larger than $2 \times 2$ cross-tables, no test could be applied whenever the expected value in $10 \%$ or more of the cells was less than 5.

\section{RESULTS:}

Figure (1): clarifies that, $74 \%$ of the studied patients were poor quality of life after coronary artery bypass grafting.

Table (1): this table showed that, for patient's poor quality of life, $87 \%$ of them were related to general health, $85 \%$ of them were poor quality regarding social functioning, and $70 \%$ of them were related to physical functioning, and vitality. Regarding patient's good quality, $87 \%$ of them were related to role limitation due to emotional 
problems, $60.0 \%$ of them related bodily pain domain, and $55 \%$ of them were related to mental health.

Table (2): clarifies that, there was statistically significance relation between patient's sex, work, marital status, family income, educational level, presence of elevator, and floor number and their total quality of life after coronary artery bypass grafting $(\mathrm{p}<$ 0.05), while there was no statistically significant relation between patient's age, and number of family members and their total quality of life after coronary artery bypass grafting.

Table (3): illustrates that, there was statistically significant relation between presence of hypertension, hyperlipidemia, diabetes mellitus, smoking, first time undergone operation and total quality of life for patients after coronary artery bypass grafting $(\mathrm{p}<0.05)$. while, there was no statically relation between presence of heart failure and coronary artery disease and total quality of life.

Table (4): clarifies that there was statistically significant relation between body mass index (BMI) and patient's quality of life.

\section{Total Quality of life}

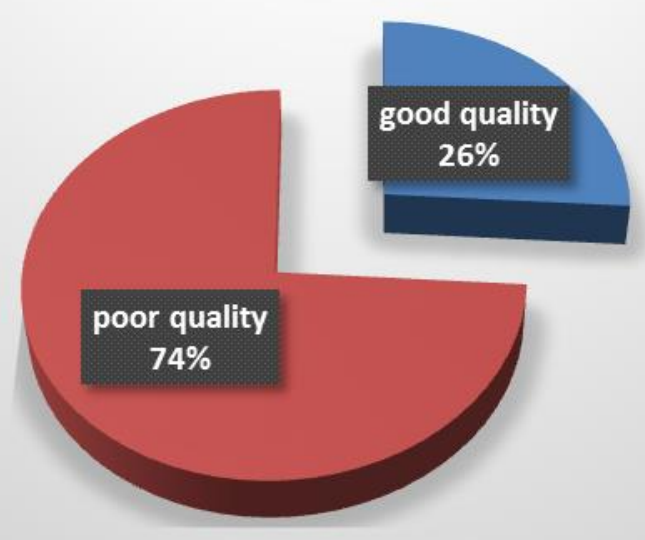

aood quality

n poor quality

Figure (1): Distribution of the studied patients with coronary artery bypass grafting surgery according to their total quality of life $(n=100)$ : 
Table (1): Domains of quality life among studied patients after coronary artery bypass grafting $(\mathrm{n}=100)$ :

\begin{tabular}{|l|c|c|c|c|}
\hline \multirow{2}{*}{\multicolumn{1}{|c|}{ Quality of life domains }} & \multicolumn{2}{c|}{ poor quality } & \multicolumn{2}{c|}{ good quality } \\
\cline { 2 - 5 } & $\mathbf{N}$ & $\%$ & $\mathbf{N}$ & $\%$ \\
\hline Physical functioning & 70 & 70.0 & 30 & 30.0 \\
\hline Role limitation due to physical health & 59 & 59.0 & 41 & 41.0 \\
\hline Bodily pain & 40 & 40.0 & 60 & 60.0 \\
\hline General health & 87 & 87.0 & 13 & 13.0 \\
\hline Energy/Vitality & 70 & 70.0 & 30 & 30.0 \\
\hline Social functioning & 85 & 85.0 & 15 & 15.0 \\
\hline Mental Health or emotional wellbeing & 45 & 45.0 & 55 & 55.0 \\
\hline $\begin{array}{l}\text { Role limitation due to emotional } \\
\text { problems }\end{array}$ & 13 & 13.0 & 87 & 87.0 \\
\hline
\end{tabular}


Table (2): Relation between patients' socio-demographic characteristics and their total quality of life $(n=100)$ :

\begin{tabular}{|c|c|c|c|c|c|c|}
\hline \multirow[t]{2}{*}{ patients' characteristics } & \multicolumn{2}{|c|}{ poor quality } & \multicolumn{2}{|c|}{ Good quality } & \multirow[t]{2}{*}{$\mathbf{X}^{2}$} & \multirow[t]{2}{*}{ P-value } \\
\hline & $\mathbf{N}$ & $\%$ & $\mathbf{N}$ & $\%$ & & \\
\hline \multicolumn{5}{|l|}{ Age/years } & \multirow[b]{4}{*}{.318} & \multirow[b]{4}{*}{.204} \\
\hline $49<60$ & 48 & 64.9 & 17 & 65.4 & & \\
\hline $60<70$ & 22 & 29.7 & 5 & 19.2 & & \\
\hline$\geq 70$ & 4 & 5.4 & 4 & 15.4 & & \\
\hline \multicolumn{5}{|l|}{ Sex } & \multirow{3}{*}{4.0} & \multirow{3}{*}{$.038^{*}$} \\
\hline Yes & 48 & 64.9 & 11 & 42.3 & & \\
\hline No & 26 & 35.1 & 15 & 57.7 & & \\
\hline \multicolumn{5}{|l|}{ Educational level } & \multirow{5}{*}{$F=4.03$} & \multirow{5}{*}{$.047 *$} \\
\hline Illiterate & 5 & 6.8 & 1 & 3.8 & & \\
\hline Read and write & 16 & 21.6 & $\mathbf{3}$ & 11.5 & & \\
\hline Secondary & 42 & 56.8 & 13 & 50.1 & & \\
\hline University & 11 & 14.8 & 9 & 34.6 & & \\
\hline \multicolumn{5}{|l|}{ Marital status } & \multirow{4}{*}{$F=4.17$} & \multirow{4}{*}{$.048^{*}$} \\
\hline Married & 60 & 81.1 & 25 & 96.2 & & \\
\hline Divorced & 5 & 6.8 & 1 & 3.8 & & \\
\hline Widowed & 9 & 12.1 & $\mathbf{0}$ & 0.0 & & \\
\hline \multicolumn{5}{|l|}{ Work } & \multirow{3}{*}{6.52} & \multirow{3}{*}{$.010^{*}$} \\
\hline Yes & 27 & 36.5 & 17 & 65.4 & & \\
\hline No & 47 & 63.5 & 9 & 34.6 & & \\
\hline \multicolumn{5}{|l|}{ income } & \multirow{3}{*}{4.04} & \multirow{3}{*}{$.038^{*}$} \\
\hline Enough & 48 & 64.9 & 11 & 42.3 & & \\
\hline Not enough & 26 & 35.1 & 15 & 57.7 & & \\
\hline \multicolumn{5}{|c|}{ Number of family members } & \multirow{3}{*}{.165} & \multirow{3}{*}{.436} \\
\hline $1-3$ & 17 & 23.0 & 7 & 26.9 & & \\
\hline $4-6$ & 57 & 77.0 & 19 & 73.1 & & \\
\hline \multicolumn{5}{|l|}{ Floor number } & \multirow{6}{*}{$F=4.4$} & \\
\hline First & 3 & 4,1 & 1 & 3.8 & & \\
\hline Second & 14 & 18.9 & 10 & 38.5 & & $.049 *$ \\
\hline Third & 36 & 48.6 & 12 & 46.2 & & \\
\hline Fourth & 13 & 17.6 & \begin{tabular}{|l|l|}
0 \\
\end{tabular} & 0.0 & & \\
\hline Others & 8 & 10.8 & 3 & 11.5 & & \\
\hline Presence of elevator & & & & & & \\
\hline Yes & 13 & 17.6 & 11 & 42.3 & 6.45 & $.011 *$ \\
\hline No & 61 & 82.4 & 15 & 57.7 & & \\
\hline
\end{tabular}

*statistically significant $\longrightarrow \quad \mathrm{p}<0.05$

Chi square test $\rightarrow \mathrm{F}$

Anove test 
Table (3): Relation between patients' medical and surgical history and their total quality of life $(n=100)$ :

\begin{tabular}{|c|c|c|c|c|c|c|}
\hline \multirow[t]{2}{*}{ patients' characteristics } & \multicolumn{2}{|c|}{ poor quality } & \multicolumn{2}{|c|}{ Good quality } & \multirow[t]{2}{*}{$\mathbf{X}^{2}$} & \multirow[t]{2}{*}{ P-value } \\
\hline & $\mathbf{N}$ & $\%$ & n & $\%$ & & \\
\hline \multicolumn{5}{|l|}{ Heart failure } & \multirow{3}{*}{.143} & \multirow{3}{*}{.706} \\
\hline Yes & 43 & 58.2 & 14 & 53.8 & & \\
\hline No & 31 & 41.8 & 12 & 46.2 & & \\
\hline \multicolumn{5}{|l|}{ Coronary artery disease } & \multirow{3}{*}{.103} & \multirow{3}{*}{.748} \\
\hline Yes & 40 & 54 & 15 & 57.6 & & \\
\hline No & 34 & 46 & 11 & 42.4 & & \\
\hline \multicolumn{5}{|l|}{ Hypertension } & \multirow[t]{3}{*}{3.7} & \multirow[t]{3}{*}{$.044 *$} \\
\hline Yes & 35 & 47.3 & 18 & 69.2 & & \\
\hline No & 39 & 52.7 & 8 & 30.8 & & \\
\hline \multicolumn{5}{|l|}{ Hyperlipidemia } & \multirow[t]{3}{*}{6.1} & \multirow[t]{3}{*}{$.013 *$} \\
\hline Yes & 25 & 33.8 & 16 & 61.5 & & \\
\hline No & 49 & 66.2 & $\mathbf{1 0}$ & 38.5 & & \\
\hline \multicolumn{5}{|l|}{ Diabetes Mellitus } & \multirow{3}{*}{6.3} & \multirow{3}{*}{$.011 *$} \\
\hline Yes & 44 & 59.5 & 8 & 30.8 & & \\
\hline No & 30 & 40.5 & 18 & 69.2 & & \\
\hline \multicolumn{5}{|l|}{ Smoking } & \multirow{3}{*}{7.4} & \multirow{3}{*}{$.008 *$} \\
\hline Yes & 14 & 18.9 & 12 & 46.2 & & \\
\hline No & 60 & 81.1 & 14 & 53.8 & & \\
\hline \multicolumn{5}{|l|}{ First time operation } & \multirow{3}{*}{5.80} & \multirow{3}{*}{$.050 *$} \\
\hline Yes & 74 & 100.0 & 24 & 93.2 & & \\
\hline No & $\mathbf{0 . 0}$ & 0.0 & 2 & 7.7 & & \\
\hline
\end{tabular}

Table (4): Relation between patients' body mass index and their quality of life $(n=100)$ :

\begin{tabular}{|c|c|c|c|c|c|c|}
\hline \multirow[t]{2}{*}{ patients' characteristics } & \multicolumn{2}{|c|}{ poor quality } & \multicolumn{2}{|c|}{ Good quality } & \multirow[t]{2}{*}{$\mathbf{X}^{2}$} & \multirow[t]{2}{*}{ P-value } \\
\hline & $\mathbf{N}$ & $\%$ & $\mathbf{n}$ & $\%$ & & \\
\hline Body mass index & & & & & \multirow{4}{*}{9.98} & \multirow{4}{*}{$.007 *$} \\
\hline Normal Weight 18.5- 24.9 & 6 & 8.1 & 6 & 23.1 & & \\
\hline Overweight 25- 29.9 & 30 & 40.5 & 15 & $\mathbf{5 7 . 7}$ & & \\
\hline Obesiy $\geq 30$ & 38 & 51.3 & 5 & 19.2 & & \\
\hline
\end{tabular}




\section{DISCUSSION:}

Coronary artery bypass surgery is a complex procedure that affects many body systems such as cardiovascular and respiratory systems so the physiological effect of those systems will be worsening. Post-operative period may contribute to many limitations including physical capacity restriction. Patients cannot do activity of daily life or work effectively, that make poor financial. Moreover, it may disturb the mental health that make poor QOL (Boontuam, Kaewkhuntee, Nualnim, \& Thirapatarapong., 2018). Quality of life is defined as a multi-dimensional assessment of an individual's perception of the physical, social and psychological aspects that are affected by the disease and its treatment. Various studies on investigating the factors that affected the quality of life have demonstrated there is relationship between quality of life, demographic factors and patient related characteristics (Pulimala et al, 2020).

For the bodily pain domain of quality of life, three-fifths of studied patients have good quality related to the pain domain. From the point of view of the researcher, this may be due to sufficient rest and sleep, greater dependence on medicinal products, and avoiding stressful activities. These finding comes in line with Pac`aric et al., (2020) who showed that the greatest improvement is in the domain of pain (BP), which can be explained by the fact that currently in Croatia, the pain is treated better and that patients follow pain therapy recommendations. Also, this in agreement with Peric et al., (2017) who reported that after two years of coronary artery bypass grafting, symptomatology is significantly improved, patients less complain of pain in the chest, shortness of breath, and fatigue when walking and palpitations. In addition, Saboula, Hussein, \& Habouh., (2020) who stated that Pain syndromes that occur after cardiac surgery can be numerous and of visceral, musculoskeletal, or neurogenic origin. The results of this study illustrated that the reported level of pain after surgery decreased the quality of life for patients and affects their comfort level. These finding improved and the patient-reported an improved level of pain after implementing the home-based nursing intervention.

These results are inconsistent with Albilasi et al., (2018) who detailed that bodily pain domain was affected, patients had pain that interfered with their normal work (including both work outside the home and housework). Also, this in agreement with 
Lavdaniti et al., (2015) Who reported that patients had lower scores in the pain domain which interfered with the patient's daily activity. In addition, Maoa, Sunb, \& Zhangc., (2020) Pain is one of the ineffectively managed symptoms that affect the recovery status of cardiac surgery patients, and negatively affects a patient's health in terms of reducing QOL, physical functions, impaired sleep, and enhance the economic burden of the treatment. Analysis of this study also showed physical activity intervention moderately improves the scores of in body pain in post-CABG patients.

Regarding the physical functioning domain of quality of life, most of the studied patient weren't satisfied with their level of daily activities functioning. From the point of view of the researcher, this may be due to the physical restriction due to surgical site at chest and site of multiple grafts from leg or hand disrupted them from doing vigorous activities. Also, slightly less than half of them live on the third floor and more than three- quarter of the studied patients hadn't elevators in their housing and this can affect climbing several flights of stairs. In addition, less than half of them were overweight and one fifth of them had diabetes that negatively affect wound healing and physical mobility.

This finding come in line with Fakhrzad, Goudarzi, Barouni, Kojuri, \& Jahani., (2016) who found the lowest score was related to the physical functioning domain after coronary artery bypass grafting. In addition, Albilasi et al., (2018) reported that the physical functioning domain was affected after coronary artery bypass grafting. Also, Lavdaniti et al., (2015) Who reported a low score for physical functioning domain. According to Maoa, Sunb, \& Zhangc., (2020), physical functioning (PF) is the personal potential to perform physical activity (PA) in daily life. PF reflects physical fitness, motor function and control, and daily PA. Results of the analysis revealed physical functioning in post-CABG patients decreased after $\mathrm{CABG}$ but there was PF significant improvement when patients received physical activity intervention.

These results are inconsistent with Peric et al., (2017) who detailed that after twoyears of $\mathrm{CABG}$, there is an additional improvement in the section of physical mobility in spite of this improvement, the patients were spared major physical effort. Also, this in agreement with results found by Pulimala et al., (2020) who evaluate health related quality of life after coronary artery bypass grafting and reported higher scores 
in a physical functioning domain. Also, this in agreement with Moreira \& Grilo., (2019), who reported that patients had physical functioning improvement after surgery, this is due to the elaboration of the program, based on the adequate physical exercise to the abilities of each patient submitted to coronary artery bypass grafting, is fundamental in the reduction of post-operative complication and essential in the clinical discharge.

\section{As regard the role limitation due to physical problems (RP) of quality of life,} more than half of studied patients had poor quality due to limited ability to engage in normal daily activities and slightly less than half of them were overweight. These findings come in line with Pulimala et al. (2020) who found the least score of quality of life in role limitation due to physical problems. In addition, Jalal, Nabiamjad, Safdari, Raouli, and Haghani., (2015) who found the lowest scores for role physical domain. Also, this finding is in congruent with Fakhrzad, Goudarzi, Barouni, Kojuri, \& Jahani., (2016) who reported the lowest score in role limitation physical after CABG. According to, Pac ${ }^{2}$ aric et al., (2020) who reported that after rehabilitation, the lowest score was recorded in limitation due to physical difficulties. This can be explained by the fact that these patients were more than 60 years, and that there were side effects after surgery, and the frequency of risk factors in these patients increased.

These findings are inconsistent with Albilasi et al., (2018) who found improvements in role limitation due to physical problems domain. In addition, the study conducted by Lavdaniti et al., (2015) that reported improved score related to role physical domain.

For the Social functioning (SF) domain of quality of life, most of the studied patients had poor quality of social life, they hadn't participated in normal social activities with their families, friends, neighbors or groups. From the point of view of the researcher, this may be attributed to a reduced level of physical functioning impacting their social lives, as well as being older and having chronic illnesses, according to the researcher. Furthermore, because of the elderly and those with chronic diseases' fears of illness and death, this research took place during the outbreak of the Covid 19 virus, which resulted in isolation from social gatherings and crowds. 
These findings come in line with Pačaric et al., (2020) who reported that the social functioning domain (SF) in this study is estimated lower and didn't change over time in comparison to other studies. That can be explained due to higher rates of comorbidities and older-aged patients, as well as inadequate support from the community. In addition, Albilasi et al., (2018) who reported negatively affected social functioning after CABG in his study. Also, Lavdaniti et al., (2015) Who reported lower score in social functioning domain. These results are inconsistent with Moreira \& Grilo., (2019) who showed significant improvement in a social functioning domain, this is due to the patients undergone cardiac rehabilitation program. Also, this in agreement with results found by Abdallah et al., (2020) who noticed more improvement in the social domain.

\section{In relation to emotional wellbeing or mental health (MH) of quality of life,} more than half of studied patient had good quality related to emotional health, they had a feeling of calm, peace, contentment and happiness. From the point of view of the researcher, more than three-fifths of the studied patients were married and less than three quarters of them living with their sons, the spousal life decreases comorbidities, the patients receive emotional support and assistance from their partners and living with family atmosphere reduces frustration, despair and depression. Also, the patients have faith in god and complete satisfaction with god judgments. These findings come in line with Pulimala et al., (2020) who reported that higher scores related the mental health. In addition, Moreira \& Grilo., (2019) who studied the quality of life after coronary artery bypass graft surgery- results of cardiac rehabilitation programme and showed that there is a significant improvement in mental health due to cardiac rehabilitation program application.

These results are inconsistent with Albilasi et al., (2018) who found that Patients reported anxiety, fear of future, nervousness, and despair and frustration. Also, this study is an agreement with Lavdaniti et al., (2015) who reported the lowest scores in mental health.

\section{For the role limitation due to emotional problems (RE) domain of quality of} life, most of studied patients have good quality in their emotional role. This finding is an expected outcome from improved emotional wellbeing domain for them. These 
findings come in line with Fakhrzad, Goudarzi, Barouni, Kojuri, \& Jahani., (2016) who reported improved role emotional domain for patients after coronary artery bypass grafting. In addition, Pulimala et al., (2020) reported higher scores in the role emotional domain after CABG. Also, the study conducted by Lavdaniti et al., (2015) that reported high quality in role emotional domain of quality of life. According to the study conducted by Moreira \& Grilo., (2019) as quality of life after coronary artery bypass graft surgery- results of cardiac rehabilitation program. It shown improved role emotional role after patients undergone cardiac rehabilitation program.

These results are inconsistent with Pac ${ }^{2}$ aric et al., (2020) who reported poor results observed in the emotional role. These finding can be explained with the number of symptoms of illness and psychological difficulties as fear, postoperative course, and concern for the future. Also, Mendonca, \& Andrade., (2015) were reported lower scores of role emotional role domain.

Regarding the general health (GH) domain of quality of life, most of studied patients had poor satisfaction with their general health domain, they predicted that their health may be worsened at any time and they are at high risk for re-developed coronary artery occlusion and re-admitted to the hospital again. From the point of view of the researcher, this finding may be due to limited physical activity that affected the time that patients can spend in their work and limited patient's capabilities for caring for themselves, three-fifths of studied patients had low quality in vitality or energy domain, they feel tired, downhearted and worn-out most of time and the majority of them socially isolated.

These findings come in line with Abdallah et al., (2020) who found that the lowest improvement in patient's general health perception due to limited physical activity. Also, Jalal, Nabiamjad, Safdari, Raouli, \& Haghani., (2015) had an agreement with the finding with the current study. These findings are inconsistent with Pac ${ }^{2}$ aric et al., (2020) who reported that After the CABG surgery, there was an improvement in general health $(\mathrm{GH})$, which may be related to the reduction or elimination of angina and chest pain. In addition, Albilasi et al., (2018) who reported that the patients enjoyed good general health after CABG. This finding explained as the government provides fee health-care services for all citizens, patients in this study were not having 
any concerns about the surgery discharge before and after the operation. Therefore, post-operative complications will be decreased.

For energy or vitality health (VT) domain of quality of life, most of the studied patients had poor quality related to vitality domain, patients reported tiredness, downhearted and blue most of the times and hadn't energy to do daily activities and work inside and outside house. From the point of view of the researcher, this finding is expected as more than one third of studied patient elder than sixty years old and those patients had comorbidities as hypertension and diabetes. Also, slightly less than half of them are obese patients that may negatively affect quality of life of those patients.

These findings come in line with Pačaric et al., (2020) who reported a slightly lower score in vitality health for the patients. In addition, Pulimala et al., (2020) who reported the least scores in the vitality health domain. These findings are inconsistent with Albilasi et al., (2018) who reported higher scores in vitality domain. In addition, Moreira \& Grilo., (2019) who reported high quality related vitality health after receiving cardiac rehabilitation program. Also, Fakhrzad, Goudarzi, Barouni, Kojuri, \& Jahani., (2016) who reported high quality related vitality health.

For total quality of life for patients after CABG, three quarters of the study population had poor quality of life. This finding come in line with Hafizan, Rosliza, Juni, \& Arif., (2018) who reported that as compared to normal general population of Malaysia, even though the score for QOL domains in this study found to be low. According to, Verwijmeren et al., (2018) who studied Preoperative determinants of quality of life a year after coronary artery bypass grafting, the majority of patients physical HRQL hardly changed, as was reflected by a mean increase of 0.7 points and low quality of life after surgery.

These findings are inconsistent with Perrotti et al., (2019) who reported that quality of life observed to improve up to 5 years after surgery, and remained significantly improved at 10 years, indicating that the patients seem to have yielded benefit from the operation, as perceived and reported via the QoL scores. In addition, Murshid et al., (2020) reported improved quality of life after coronary artery bypass 
grafting surgery. Also, this in agreement with Rahman, Flora, Haider, Jahan, \& Zafreen., (2018) Who found improved quality in physical component summary (77.4 \pm 12.37 ) and psychological component summary (79.88 \pm 11.03$)$. According to, Ambina, Shalimol, \& Anjana., (2019) showed that overall quality of life of post CABG patients $97 \%$ had good quality of life with mean score of 69.22 and standard deviation 9.368 and Fakhrzad, Goudarzi, Barouni, Kojuri, \& Jahani., (2016) who reported coronary artery bypass grafting led to more improvement in patients' quality of life. Also, this came in congruent with Peric et al., (2017) who reported that more than half of studied patients had improved quality of life.

\section{For relation between patients' socio-demographic characteristics and their} total quality of life, there were statistically significant relation between patients' sex, education, marital status, work, income, floor number, and presence of elevator and their quality of life. This may be due to patients be married make them strong and have assistance and emotional support from their partners, and patients with low educational level had low awareness with disease, surgery, and outcome. Variation in female and male social responsibilities and hormonal changes in women affect quality of life according to gender.

According to, Mahmoud, Alaa Eldin, \& Hussein., (2016) There is no debit that education has greatest effect on quality of life. As the relation between level of education and quality of life dimensions, there was a high statistically significant relation between level of education and overall average score of quality of life. This can be explained through the fact that educated person maintains their life style and health related behavior than the poorly educated persons. Also, there was a high statistically significant relation between occupation and overall average score of quality of life.

These findings come in line with Jalal, Nabiamjad, Safdari, Raouli, \&Haghani, (2015) who reported that the married individuals had a better QOL than other group, this showed as being alone is a risk factor for the individual's health which can bring early mortality. Possibly, being alone give rise to the emergence of non-hygienic behaviors, excessive depression, failure in immune system, and other physical and psychological disturbances. Also, this study found that economic and social status 
seriously affects the individual's appreciation of the disease and satisfies their sense of wellbeing. Improper economic status can produce tension, dissatisfaction with life, and concern about therapeutic cares.

This in agreement with, Hafizan, Rosliza, Juni, \& Arif. (2018) who found Several sociodemographic characteristics (employed, married, high education level) were associated with good score of SF-36 QOL domains among the respondents. Also, Bakhsh et al., (2016) reported significant relation at educational level, and income level with their total quality of life. This study showed that those who had enough income and higher educational level experienced better HRQOL, while other covariates (age, and sex) not significantly were not found to be determinant for HRQOL. In addition, Verwijmeren et al., (2018) reported Possible risk factors for change in HRQL that are readily available such as female gender, older age, and socio-economic status have been associated with worse HRQL following cardiac surgery.

These findings come in line with Pulimala et al., (2020) who showed that sex has significant relation with quality of life. This finding explained through variation in social functions, responsibilities of the household, and women may feel greater burden than men when they can't perform their role effectively. Also, the single subjects have less improvement in health when compared to married subjects and the patients with higher education level were less satisfied with themselves and their personal relationship. But this study disagrees with the current study in age related relation with total quality of life, there is growth in health domains of quality of life in patients less than sixty years because those patients usually possess good physical conditioning, mental function, improvement in cardiac status and the lower incidence of comorbidities than elderly.

These findings are inconsistent with, Jalal, Nabiamjad, Safdari, Raouli, and Haghani., (2015) who reported there was no significant statistical relation between educational level and QoL. However, individuals with higher educational levels had higher average of QoL compared with other groups having elementary school education or illiterate. In addition, Pačaric et al., (2020) who reported there was no significant relationship between sociodemographic characteristics and QoL. That 
finding may explained by that the fact the participants in this study rated their quality of life worse than the participants in similar studies in other countries. Also, there is agreement with, Fakhrzad, Goudarzi, Barouni, Kojuri, \& Jahani., (2016) who reported that demographic variables had no significant effects on score change in quality of life.

For relation between patients' medical and surgical history and their total quality of life, there were statistically significant relation between diabetes, hypertension, and dyslipidemia, smoking and the first-time patients undergone coronary artery bypass grafting. This if finding explained through presence of comorbidities may have negative effect on patient's quality of life.

This finding come in line with Pulimala et al., (2020) who reported presence of more co-morbidities influenced the improvement in quality of life. multimorbidity was observed more in elderly patients than younger patients that may be one of the reasons of change in QOL. Smoker subjects have less quality of life when compared to nonsmoker participants. In addition, Abdallah et al., (2020) who found hypertension, hypercholesterolemia and smoking were independent predictors for worsening quality of life.

In addition, Sajobi et al., (2018) reported baseline risk factors including diabetes mellitus, hypertension and smoking were predictive of the differences in quality of life. In fact, individuals in the low or decreased quality subgroups are more to be patients with diabetes mellitus who smoke. In addition, Bakhsh et al., (2016) reported that clinical variables, diabetes comorbidity, hypertension, previous MI, and hypercholesterolemia were found to be important determinant for HRQOL.

These findings are inconsistent with Jalal, Nabiamjad, Safdari, Raouli, and Haghani., (2015) who reported there was no significant statistical correlation between smoking and QOL. However, QOL among smokers is lower than those who quitted smoking or don't smoke at all and There is a reverse relationship between increase in tobacco and QOL. This in agreement with Pac ${ }^{2}$ aric et al., (2020) who noted that the risk factors and comorbidities as hyperlipidemia, hypertension, diabetes, and smoking weren't predictors of poorer quality of life assessment. That finding may explained by that the fact the participants in this study rated poor quality of life regardless of risk factors and it is likely that all cardiac patients have almost all or most of the risk factors. 
For relation between patient's body mass index and their total quality of life, there was highly statistical relation between BMI and quality of life. This finding comes in line with Sajobi et al., (2018) reported that body mass index was predictive of the differences in quality of life. In fact, individuals in the low or decreased quality subgroups are more to be obese patients. In addition, Bakhsh et al., (2016) reported that body mass index $>35$ was found to be important determinant for worsened quality of life. Also, Jalal, Nabiamjad, Safdari, Raouli, \&Haghani, (2015) who reported that there is a significant relationship between body mass index and change in QoL Score. This finding is inconsistent with Pačaric et al., (2020) who noted that the body mass index wasn't predictors of poorer quality of life assessment. That finding may explained by that the fact the participants in this study rated poor quality of life regardless of risk factors and it is likely that all cardiac patients have almost all or most of the risk factors.

\section{CONCLUSION:}

According to the findings of the current study, it can conclude that about three-quarter of the studied patients had poor QOL, most affected domains are general health domain followed by social functioning domain then physical functioning domain and vitality. There was statistically relation between QOL and patient's sex, educational level, work, smoking, marital status, income, floor number and presence of elevator. Also, there was statistically relation between QOL and presence of diabetes, hypertension, hyperlipidemia, smoking, first time surgery and body mass index and patients' quality of life.

\section{RECOMMENDATION:}

In the light of the results of the present study, the following recommendations are suggested:

1. Before and after coronary artery bypass grafting, patients and their families should be given knowledge and practice through videos, models, and printed materials.

2. All CABG patients should be engaged in a cardiac rehabilitation program and be motivated to speed up their recovery. 
3. Standards of care and guidelines should be developed to improve the patient's quality of life post $\mathrm{CABG}$

\section{Further Research: -}

Repeat this study as a quality of life five, ten, and twenty years after coronary artery bypass surgery.

\section{REFERENCES:}

Abdallah, M., Mamdouh, S., Gilany, A., Abdel-Aziz, W., Farag, O., \& ElAdawy, N. (2020). Short-term outcomes of surgical myocardial revascularization on health-related quality of life: a validation of the Arabic Mac New heart disease questionnaire. Journal of The Cardiothoracic Surgeon, 28 (19). 1-17

Ajtahed, S., Rezapour, T., Etemadi, S., Moradi, H., Asgarabad, M., \& Ekhtiari, H. (2019). Efficacy of Neurocognitive Rehabilitation After Coronary Artery Bypass Graft Surgery in Improving Quality of Life: An Interventional Trial. Journal of Front Psychology, 10. 1759. Doi: 10.3389/fpsyg.2019. 01759

Albilasi, T., Albilasi, B., Alonazi, M., Al-ruwaili, W., Almarkhan, M., Alanazi, N., \& Alotaibi, H. (2018). Assessment and Evaluation of the Quality of Life of Saudi Patients Underwent Coronary Artery Bypass Graft (2-5 years). The Egyptian Journal of Hospital Medicine, 70 (3), 452-457

Ambina, K., Shalimo, U., \& Anjana, A. (2019). Quality of Life and Quality of Sleep among Post CABG Patients. Indian Journal of Public Health Research \& Development, 10 (12), 154-159

Bakhsh, R., Javanbakt, M., Sadeghi, M., Mashayekhi, A., Ghaderi, H., \& Rabiei, K. (2016). Comparison of health-related quality of life after percutaneous coronary intervention and coronary artery bypass surgery. journal of ARYA Atherosclerosis, 12 (3), 124-131.

Boontuam, W., Kaewkhuntee1, W., Nualnim, N. \& Thirapatarapong, W. (2018). The Relationship among Six-minute Walk Test, 12-item Short Form and the World Health Organization Quality of Life Brief in post Coronary Artery Bypass Graft Patients: A Pilot Study. Walailak Procedia, 82. (3), 1-6

Fakhrzad, N., Goudarzi, R., Barouni, M., Kojuri, J., \& Jahani, Y. (2016). Examining the Health-Related Quality of Life after Coronary Artery Bypass Grafting and Percutaneous Coronary Intervention in Iran via SF-36 and SAQ. Int Cardiovasc Res Journal, 10 (3),123-128 
Hafizan, A., Rosliza, A., Juni, M., \& Arif, M. (2018). FACTORS ASSOCIATED WITH QUALITY OF LIFE AMONG POST CORONARY ARTERY BYPASS GRAFTING PATIENTS AT A CARDIOTHORACIC CENTRE IN MALAYSIA. International Journal of Public Health and Clinical Sciences, 5 (6), 358372. Retrieved from https://doi.org/10.32827/ijphcs.5.6.358

Ibrahim, W., \& Abdalla, H. (2019). Patient Compliance toward Medication and Life Style Change after Coronary Artery Bypass Grafting in Ahmed Gassim Hospital Khartoum Locality- Sudan 2018. Journal of Nursing \& Care, 8 (4), 1-4.

Jalal, E., Nabiamjad, R., Safdari, M., Rasouli, D., \& Haghani, H. (2015). Evaluation of the Quality of Life among the Patients Undergoing Coronary Artery Bypass Grafting. Client-Centered Nursing Care, 3(1), 151-157

Khalifa, Y., Eisa, K., Bary, M., Ismail, H., \& Taha, A. (2018). Short term outcome of coronary artery bypass graft surgery: Evaluation of recently established cardiac center. Journal of the Egyptian society of Cardio-Thoracic surgery, 36 (1), 24-29. Retrieved from https://doi.org/10.1016/j.jescts.2017.12.003

Lavdaniti, M., Tsiligiri, M., Palitzika, D., Chrysomallis, M., Douli, M., \& Drosos, G. (2015). Assessment of Health Status Using SF-36 Six Months after Coronary Artery Bypass Grafting: A Questionnaire Survey. Health Science Journal., 9. 1-7

Mahmoud, S., Alaa Eldin, S., \& Hussein, R. (2016). Relation between Quality of Life and Sex of Patients Post Coronary Artery Bypass Surgery. Journal of ASNJ. 18 (1). 137-160

Mahmoud, S., Alaa-Eldin, S, \& Husssein, R. (2016). Quality of life and sex of patients post Coronary Artery Bypass Surgery. Alexandria University Faculty of Nursing Journal, 18 (1). 137-160

Maoa, Y., Sunb, L., \& Zhang, J. (2020). Effects of Physical Activity on Quality of Life of Coronary Artery Bypass Grafted Patients: Re Examining the Evidence from Randomized Clinical Trials Through Systemic Review. Revista Argentina de Clínica Psicológica, XXIX (4), 780-788

Mendonça, K., \& Andrade, T. (2015). Patient's Perception About Coronary Artery Bypass Grafting. Brazilian Journal of Cardiovasc Surg ,30(5),544-51

Moreira, J., \& Grilo, E. (2019). Quality of life after coronary artery bypass graft surgery - results of cardiac rehabilitation programme. Journal of exercise rehabilitation, 15(5), 715-722 
Murshid, S., AlGarmoushi, O., Aljezani, K., Albarakati, R., Bawazir, K., \& Sultan, S. (2020). Post-cardiac surgery health related quality of life: A Saudi crosssectional study in Jeddah. WORLD FAMILY MEDICINE/MIDDLE EAST JOURNAL OF FAMILY MEDICINE, 18 (1), 119-124

Pac`aric', T., Turk, T., Eric, I., Orkic', Ž., Eric', A., 'Srb, A., Farc`ic', N., Barac', I., \& Nemc 'ic', A. (2020). Assessment of the Quality of Life in Patients before and after Coronary Artery Bypass Grafting (CABG): A Prospective Study.Int. J. Environ. Res, 17(4),1417

Peric, V., Stolic, R., Jovanovic, A., Grbic, R., Lazic, B., Sovtic, S., \& Borzanovic, M. (2017). Predictors of Quality-of-Life Improvement after 2 Years of Coronary Artery Bypass Surgery. Ann Thorac Cardiovasc Surg, 23(5), 233-238

Perrotti, A., Ecarnot, F., Monaco, F., Dorigo, E., Monteleone, P., Besch, G., \& Chocron, S. (2019). Quality of life 10 years after cardiac surgery in adults: a longterm follow-up study. Journal of Health and quality of life outcome, 17 (1), 88

Pulimala, S., Ghanta, V., Kola, S., Kavuri, P., Kancherla, H., Premika, S., \& Swaroopa, M. (2020). Assessment and evaluation of health related quality of life after coronary artery bypass grafting (CABG) in a tertiary care teaching hospital. Indian Journal of Pharmacy and Pharmacology. 7(2). 136-141. Retrieved from https://doi.org/10.18231/j.ijpp.2020.023

Rahman, A., Flora, M., Haider, R., Jahan, R., \& Zafreen, F. (2018). Health Related Quality of Life after Cardiac Surgery. JAFMC Bangladesh, 4 (1), 51-53

Saboula, N., Hussein, A., Habouh, A. (2020). Effect of Home-based-Nursing Intervention on Knowledge, Daily Living Activities and pain for Patients after Coronary Artery Bypass Graft. Tanta Scientific Nursing Journal, 18(1), 134-195

Sajobi, T., Wang, M., Awosoga, O., Santana, M., Southern, D., Liang, Z., Graham, M., JameS, M., Ghali, W., Knudtson, M., \&Norris, C. (2018). Trajectories of Health-Related Quality of Life in Coronary Artery Disease. Circulation: Cardiovascular Quality and Outcome, 11 (3), Retrieved from http://circoutcomes.ahajournals.org/lookup/suppl/doi:10.1161/CIROUTCOMES.117. $\underline{003661 /-/ D C 1}$. Access on 13/12/20120 
Silva, S., Santana, A., Silva, N., Novaes, M. (2019). VES-13 and WHOQOLbref cutoff points to detect quality of life in older adults in primary health care. Rev Saude Publica, 53 (26), 1-7.

Valkenet, K., Trappenburg, J., Hulzebos, E., Meeteren, N., \& Backx, F. (2017). Effects of a pre-operative home-based inspiratory training programme on perceived health-related quality of life in patients undergoing coronary artery bypass graft surgery. Journal Society of physiotherapy, 103 (3), 276-282. Retrieved from http://dx.doi.org/10.1016/j.physio.2016.02.007 2

Verwijmeren, L., Noordzij, P., Daeter, E., Zaane, B., Peelen, L., \& Dongen, E. (2018). Preoperative determinants of quality of life a year after coronary artery bypass grafting: a historical cohort study. Journal of Cardiothoracic Surgery,13 (1),118 


\section{جوده حياه المرضي بعد ترقيع الثريان التاجي}

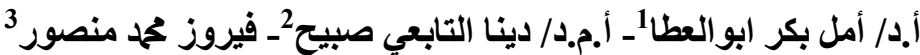

استاذ التمريض الباطني و الجر احي ـ استاذ مساعد التمريض الباطني و الجر احي2 ـ معيد التمريض الباطني و الجر احي33، كليه التمريض- جامعه بورسعيد

\section{الخلاصة}

تتأثر جودة الحياة للمرضى بعد ترقيع الثريان التاجي بعوامل متعدده منها العوامل النفسية والاجتماعية و الديموغر افية والخصائص المتعلقة بالمرضى. هدف البحث: تقييم جوده حياة المرضى بعد ترقيع الثريان التاجي. طرق وأدوات البحث: اجريت الدر اسه الوصفيه علي100 من مرضي ترقيع الثريان التاجي المترددين علي العيادات الخارجية بمستشفيات التأمين الصحي (السلام والنصر) و المستشفى الخاص (عطاء) بمدينة بورسعيد.حيث تم تجميع البيانات عن طريق استماره تقييم جوده حياه المرضي و تتضمن ثلاثة أجزاء ، الجزء الاول: الخصائص الاجتماعية الديموغر افية ، الجزء الثاني: التاريخ الطبي و الجراحي ، الجزء الثالث: تقييم جودة حياة المريض. النتائج: أظهرت هذه الدراسة أن 74٪ من المرضى يعانون من نوعية حياة سيئة. الأستتتاجات: يمكن أن نسنتتج أن حوالي ثلاثة أرباع المرضى الخاضعين للار اسة يعانون من ضعف جودة الحياة ، وأن المجالات الأكثر تضررًا هي مجال الصحة العامة يليه مجال الأداء الاجتماعي ثم مجال الأداء البدني والحيوية. كانت هناك علاقة إحصائية بين جوده حباه المرضي وجنس المريض و المستوى التعليمي و العمل والتدخين و الحالة الاجتماعية والدخل ورقم الطابق ووجود المصعد. كما توجد علاقة إحصائية بين جوده حياه المرضي ووجود مرض السكري وارتفاع ضغط الدم وفرط دهون الدم والتنخين و الجر احة لأول مرة ومؤشر كتلة الجسم ونو عية حياة المرضى. التوصيات : أوصت الدراسة بضرورة خضوع المرضي لبرنامج إعادة تأهيل القلب. 